
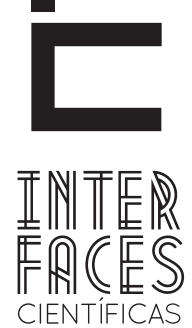

DIREITO

\title{
O PÓS-POSITIVISMO, O ATIVISMO JUDICIAL E A HUMANIZAÇ̃̃̃ DO DIREITO
}

Marlton Fontes Mota $^{1}$
Lilian Jordeline Ferreira de Melo²

\section{RESUMO}

O sistema jurídico moderno alcança hoje a chamada fase do pós-positivismo, que na aplicação da norma jurídica ao caso concreto busca trazer a concepção humanista do Direito, totalizando soluções para a pacificação social. Por meio da pesquisa bibliográfica e qualitativa, os questionamentos lançados no presente trabalho visam destacar o fato de que a sociedade vivencia um momento de grandes intervenções do direito sobre as liberdades individuais, e mesmo estando diante da afirmação de que o conflito faz parte da condição humana por ser considerado um elemento de transformação e mudança, a sua apreciação pelo judiciário poderá ter respostas com consequências positivas, de acordo com a efetividade alcançada na aplicação da norma específica. 0 processo de humanização do Direito demonstra que a extrapolação dos limites impostos pelo positivismo se faz necessária para o alcance da função social da norma jurídica e efetivamente do próprio Poder Judiciário.

\section{PALAVRAS-CHAVE}

Positivismo. Humanista. Ativismo Judicial. 


\section{ABSTRACT}

The modern legal system now reaches the call phase of post-positivism, which in applying the legal standard to the present case seeks to bring the humanist conception of law, total solutions for social peace. Through literature and qualitative research, the questions posted in this study are intended to highlight the fact that society experiences a moment of great interventions of the right to individual freedom, and even being on the claim that the conflict is part of the human condition by be considered an element of transformation and change, its assessment by the judiciary may have answers with positive consequences, according to the effectiveness achieved in the implementation of specific standard. The humanization Law process shows that the extrapolation of the limits imposed by positivism is necessary to achieve the social function of rule of law and effectively of the Judiciary.

\section{KEYWORDS}

Humanist Positivism. Judicial Activism. Right.

\section{RESUMEN}

El sistema jurídico moderno ahora llega a la fase llamada de post-positivismo, que en la aplicación de la norma legal para el presente caso busca llevar la concepción humanista de la ley, las soluciones totales para la paz social. A través de la literatura y la investigación cualitativa, las preguntas publicadas en este estudio se pretende poner de relieve el hecho de que la sociedad experimenta un momento de grandes intervenciones del derecho a la libertad individual, e incluso estar en la afirmación de que el conflicto es parte de la condición humana ser considerado un elemento de transformación y cambio, su evaluación por el poder judicial puede tener respuestas con consecuencias positivas, de acuerdo con la eficacia realizados en la aplicación de la norma específica. La Ley del proceso de humanización muestra que la extrapolación de los límites impuestos por el positivismo es necesario para lograr la función social del Estado de Derecho y con eficacia del Poder Judicial.

\section{PALABRAS CLAVE}

Positivismo humanista. Activismo judicial. Derecho. 


\section{INTRODUCÇÃO}

Questiona-se que a lei não poderia compreender e abarcar todo o direito, e nesse ponto, é cediço que o papel do julgador está imbuído na responsabilidade da melhor e mais acurada prestação jurisdicional, e no presente trabalho se pontuará sobre o recente processo de humanização do direito, perpassando em destaque pelo chamado ativismo judicial, objetivando enaltecer sobre os rumos adotados pelo sistema jurídico moderno.

A abordagem foi extraída do pensamento de diversos autores e estudiosos do tema e do olhar nas decisões dos tribunais pátrios, numa proposta de ampliar a discussão entre os profissionais do direito para, enfim, consagrar o quadro evolutivo da ampla proteção das garantias de liberdades individuais e coletivas que possibilitam as transformações sociais, numa revisão dos preceitos legais insertos no direito positivo.

Para o professor Paulo Nader (2012, p. 385), "o positivismo jurídico, que atingiu o seu apogeu no início do século XX, é hoje uma teoria em franca decadência”. E do raciocínio em questão, é possível perceber que o Direito não se compõe exclusivamente de normas, e o referido autor conclui dizendo que "as regras jurídicas têm um significado, um sentido, um valor a realizar" (NADER, 2012, p. 385).

$\mathrm{Na}$ busca por esse valor, alguns estudiosos do tema apregoam a insurgência daquilo que denominaram de 'nova hermenêutica', advinda da teoria crítica, ao lado da teoria dos direitos fundamentais.

O Direito sempre pontuou por tentar alcançar as expectativas da sociedade, concebendo garantias de liberdades e a preservação das suas bases, impondo a necessária ordem jurídica, na regulação das relações inter-humanas. E sem descartar o crucial papel do direito positivo para a sociedade, diversas e importantes transformações sociais advieram da concepção do positivismo, que possibilitou a multiplicação das fontes do direito com a diversidade dos conjuntos normativos.
Notadamente, a mobilidade dos chamados fatos sociais originadores do pensamento do legislador passaram a evidenciar sobre a necessidade de maior proteção a direitos considerados fundamentais e inerentes ao homem, a exemplo do direito à vida, à liberdade e à igualdade, exigindo-se mais do que a simples aplicação da norma, que age em subserviência ao dogmatismo legal.

Dentro dessa visão mais humanista, o Direito passa a exercer o papel de instrumento que tem 0 condão de proporcionar a paz social, com o foco na pessoa humana e na proteção da coletividade sobre o próprio indivíduo.

\section{DIREITO HUMANISTA E O DIREITO POSITIVO}

Para Nader (2012, p. 381) a concepção humanista do Direito procura "conciliar os valores justiça e segurança, captando a essencialidade do pensamento jusnaturalista, sem a inconveniência de subverter a ordem jurídica, amesquinhando o valor segurança".

Embora o Direito Positivo rejeite a abstração na concepção do próprio Direito, sem se preocupar com a valoração que possivelmente pudesse ultrapassar aquela predita pela lei, o seu declínio passa a ser observado em idêntica intensidade àquela que se verificou com o Direito Natural, quando se percebe que o Direito Positivo despreza os juízos de valor, apegando-se apenas àquilo que pode ser observado, tendo atingido o seu apogeu em decorrência da sua posição antagônica ao jusnaturalismo, de acordo com os estudiosos do tema.

O grande desafio para a humanização do Direito é o de conceber que o positivismo não alcança os chamados direitos fundamentais à inteireza do conclamo da sociedade, mas, a citada corrente proporcionou o afastamento gradativo do extremismo, podendo constatar tal fato na citação de Venosa (2010, p. 56), a saber: 
Nesse trabalho de isolamento do positivismo, há um aspecto fundamental, realçado por Kelsen, mas não esquecido, de certa maneira, pelos demais, que o conceito da norma fundamental. [...]. No ordenamento existe um encadeamento hierárquico de normas ou uma pirâmide que encontra essa norma fundamental no vértice, local mais alto. Essa norma fundamental deveria cumprir o papel de norma suprema e de estruturação de todo o Direito.

Imperioso conceber que o direito positivo não desapareceu, mas, os estudiosos e pesquisadores do tema têm admitido que a insurgência de valores, que são superiores ao direito positivo, acendeu a discussão sobre a sua insustentabilidade perante a ordem jurídica que o legitimou.

Nader (2012, p. 381) pontua que "se o jusnaturalismo puro compromete a ordem, promovendo a insegurança jurídica, o juspositivismo radical induz o jurista à alienação da causa final dos procedimentos jurídicos, que é a solução de justiça substancial". Diante disto, percebe-se sobre a necessidade de reorganização do pensamento positivismo, em virtude do processo evolutivo e mutável da própria sociedade, de forma a atender às novas exigências de proteção fundamental à pessoa humana.

A perspectiva mais humanizada do Direito se reflete, inclusive, no processo de formação dos profissionais da área que deverão ter uma atuação que ultrapasse o caráter normativista do Direito para sobrepor aos temas que são puramente dogmáticos.

Discutindo-se a respeito da necessária formação humanística do operador do Direito, destaca Rodrigues Maciel (2012, p. 2) que:

Desde 2009, a partir de determinação do Conselho Nacional de Justiça - CNJ, boa parte dos concursos voltados para a área jurídica passou a exigir formação humanística dos postulantes aos cargos públicos. O objetivo principal é conseguir selecionar profissionais que tenham condições de fazer sólida análise da sociedade, com efetiva compreensão das relações humanas tanto no âmbito global como no âmbito regional.
De forma categórica, observa-se do pensamento destacado acima, que da formação humanística poderá insurgir a verdadeira busca por soluções que desatem os problemas sociais, com foco na concretização da dignidade da pessoa humana, alterando-se o atual cenário que preconiza o pensamento lógico e estruturado que se distancia do sentimento e da intuição.

Para Dallari ([s.d.], p. 1) é por meio do "reconhecimento e da proteção dos direitos humanos o direito recupera seu sentido humanista e se restabelece o vínculo do direito com a justiça”. O referido autor compreende que "na linguagem contemporânea se nomeia como 'direitos humanos' são as faculdades e possibilidades que decorrem da condição humana e das necessidades fundamentais de toda pessoa humana" (DALLARI, [s.d.], p. 1).

0 questionamento abordado pelos doutrinadores do direito seria o acontecimento de que o positivismo, apesar de ter se centrado na razão humana e na observação dos fenômenos, aplica aos fatos jurídicos a letra fria da lei, desprovida do sentimento necessário para alcançar a percepção de que as normas jurídicas têm um valor a realizar, um sentido.

É necessário registrar que o positivismo jurídico se desenvolveu com o intuito de dar cientificidade ao Direito, num esforço de transformar o estudo do direito numa verdadeira ciência, embora avalorativa e formalista, conforme prega a "Teoria Pura do Direito" de Hans Kelsen, propondo-se a promover o conhecimento apenas dirigido ao Direito, afastando tudo aquilo que não pertença ao seu objetivo.

A respeito do tema, explica o próprio Ulhoa Coelho (2001, p. 45), que a "grande motivação da teoria pura do direito é a de definir as condições para a construção de um conhecimento consistentemente científico do direito".

Mesmo diante das elucubrações dos pensadores do direito, Pinto e Borgo ([s.d.], p. 272) afirmam que 
“não foi intencional a asseveração de Hans Kelsen, tampouco de qualquer outro doutrinador positivista, de reduzir o ordenamento jurídico a apenas um conjunto normativo" e justifica a autora que isto ocorre "sem qualquer ligação com a realidade dos jurisdicionados, ou ainda, separado do sentido de justiça”. Concluindo-se que para o positivismo, não se imaginou que poderiam ocorrer efeitos desastrosos, assim como não se previu a insurgência da natureza racional e social do homem, alicerçados pela razão e que desvinculou o princípio do justo da subordinação à lei eterna preconizada pelo direito natural, caracterizando-se, em ambas as situações, o natural processo evolutivo da sociedade.

Discussões alcançam o fato de que a sociedade vivencia um momento de grandes intervenções do direito sobre as liberdades individuais, mesmo diante da afirmação de que o conflito faz parte da condição humana, sendo considerado um elemento de transformação e mudança. O Direito, portanto, assumiu o papel de normatizar condutas estabelecidas, além de regular as relações sociais, e tem sido a normatividade do Direito o aspecto que o distingue das demais instituições sociais, sendo cediça a afirmação de que - legislador não acompanha a mobilidade dos fatos sociais à celeridade da ocorrência desses mesmos fatos, mas, o Direito permite que os seus intérpretes alcancem a solução que mais se adéque ao caso concreto, ainda que esta se consolide na resposta fundada na verdade formal.

Venosa (2012, p. 6) define a dinamicidade do Direito e a sua importância para a coesão da sociedade na busca do bem comum, da seguinte forma:

O Direito, como se acentua, é dinâmico, como dinâmica é a sociedade. Já vai longe o tempo no qual se entendia que o direito possuía verdades inafastáveis e cerradas. Em Direito não há dogmas, mas, princípios, normas e leis que podem e devem ser alterados de acordo com as necessidades sociais. [...] 0 Direito é essencialmente dialético. [...] O Direito é necessário. A sociedade não existe sem ele. Não se trata de uma criação abstrata.
Por sua vez, a problemática trazida por Fernandes de Aquino (2011, p. 111) enaltece sobre a pouca disposição dos indivíduos para a solução dos conflitos por meio do diálogo, e para o autor “a vida cotidiana consolida a segregação do convívio, bem como torna inóspita a existência de espaços públicos para a interação e comunicação humana”. E conclui seu pensamento, afirmando que "a resolução de conflitos proposta pela atividade jurisdicional não propõe uma alternativa adequada para se compreender esse momento" (AQUINO, 2011, p. 111).

Percebe-se no teor das discussões e questionamentos alinhados pelos pensadores do Direito que urge a necessidade de buscar a solução para os conflitos com vistas ao aperfeiçoamento humano, e não somente prestar a jurisdição, decidindo por decidir.

\section{ATIVISMOJUDICIAL NA HUMANIZAÇ̃̃O DO DIRETTO}

O Judiciário não ficou imune às transformações sociais das ultimas décadas no Brasil, e tal consideração se confirma com mais contundência após a promulgação da Carta Constitucional de 1988, que preconiza a protetividade dos direitos fundamentais e uma maior garantia da prestação jurisdicional.

Da mesma forma, o processo de humanização do Direito por meio das decisões judiciais traz à baila a altercação sobre a extrapolação dos limites impostos pelo positivismo na norma jurídica, que determina 0 alcance da regra ao caso concreto. Piske (2007, p. 1) se manifesta a respeito do tema, ao confirmar sobre o papel de politização do juiz ante as mudanças sociais e econômicas contempladas nas constituições modernas, assim predizendo:

O Judiciário não somente passou a solucionar os conflitos intersubjetivos de interesses, segundo o modelo liberal individualista, como também a atuar como órgão calibrador de tensões sociais, solucionando conflitos de conteúdo social, político e jurídico. (PISKE, 2007, p. 1). 
Sem dúvidas o papel do magistrado diante das aclamadas mudanças sociais e econômicas tem sido desafiador, pois, a sua decisão no caso concreto deve ponderar sobre a busca do equilíbrio na solução dos conflitos, com base nas exigências e proteção ao bem comum, enaltecendo os fins sociais da norma aplicada.

A proposta de alcançar a pacificação social na resolução das contendas deve resguardar os direitos e garantias fundamentais do indivíduo, observando todos os aspectos sociais, políticos e econômicos que permeiam os fatos que são submetidos à sua apreciação.

Embora o papel da adequação da norma jurídica às mudanças sociais, que provocam a complexidade dos conflitos, deva partir do próprio legislador, o que tem se mostrado é uma atuação proativa do Judiciário na interpretação desses fatos sociais insurgentes, dando-lhes a solução mais justa, com base nos preceitos inovadores da ordem jurídica e social.

Exemplos povoam os tribunais pátrios a respeito da aplicação prática dos princípios e preceitos do chamado pós-positivismo, que não pretende negar a importância do Direito Positivo, ao adotar princípios que o torna mais flexível e mais sensitivo, a exemplo da razoabilidade e da proporcionalidade, que estão sendo submetidos a uma ponderação de valores, conforme se lê dos julgados colacionados:

\section{Ementa}

DIREITO PROCESSUAL CIVIL E CIVIL. AÇÃO REIVINDICATÓRIA. INÉPCIA DA INICIAL. ILEGITIMIDADE PASSIVA. EXTINÇÃO DO PROCESSO SEM RESOLUÇÃO DE MÉRITO. CONSTRUÇÃO DE EDIFÍCIO. INVASÃO PARCIAL DE ÁREA CONTÍGUA. [...]. A invasão de terreno alheio por pessoa jurídica não induz, necessariamente, a legitimidade passiva de seu sócio administrador para ação reivindicatória. 0 paradigma do pós-positivismo jurídico, operando verdadeira revolução no quadro da hierarquia das normas, dota os Princípios Gerais de Direito de força normativa, com poder vinculante superior. A atividade jurisdicional não pode solucionar o caso concreto outorgando proteção a um bem jurídico em desproporcional sacrifício de outro igualmente tutelado, a pretexto do cumprimento da norma jurídica posta, sob pena de coadjuvar com a injustiça e, daí, operar verdadeira ilicitude. [...]. Detectando-se, todavia, que o reconhecimento do domínio da construção em favor do proprietário do terreno invadido - dada a desproporção entre o valor irrisório deste e o vulto daquela -, importa violação do princípio da proporcionalidade, [...]. Reconhecida a obrigação do invasor de boa-fé indenizar em dinheiro [...]. TJ-MG - 100240283822570012 MG 1.0024.02.8382257/001(2) (TJ-MG)Data de publicação: 01/06/2009 Ementa

OINDIVÍDUO À POSIÇÃO DE CENTRO DO SISTEMA JURÍDICO. NO CASO DOS PRESENTES AUTOS, ESTÁ PATENTE A AMEAÇA À LIBERDADE FÍSICA DA PACIENTE, [...]. 0 pós-positivismo jurídico impõe outra atitude dos operadores do direito, havendo possibilidade, até mesmo, de afastar-se regra escrita para aplicar normas fundadas em princípios de direito, em busca da realização da justiça no caso concreto. Assim, em que pese o fato ser diferente do caso já massificado no Supremo Tribunal Federal no que tange à anencefalia, outros casos congêneres devem ser cuidados com amáxima cautela que se exige frente à complexidade do tema, que impõe ao poder judiciário despir-se dos mais íntimos sentimentos e valores para decidir sobre a questão em tela[...].TJ-RJ - HABEAS CORPUS HC 00469836720148190000 RJ 0046983-67.2014.8.19.0000 (TJ-RJ)Data de publicação: 26/09/2014. (Grifos nosso).

Para Silva (2010, p. 2) o cenário jurídico nacional tem vivenciado a postura da Suprema Corte em proferir "várias decisões de natureza nitidamente ativista-concretista, dando total preponderância aos princípios, implícitos ou explícitos, espraiados na Lei Magna”, e o autor coloca, a título de exemplo, "a recente decisão sobre a vedação do nepotismo aos Poderes Legislativo e Executivo, que deu origem à súmula vinculante $n^{0} 13$, não obstante a ausência de decisões reiteradas". Outra situação destacada por Silva (2010, p. 3) "seria Súmula vinculante $n^{0} 11$ do Supremo Tribunal Federal ao exigir as razões por escrito da excepcionalidade do uso de algemas inovou no Ordenamento Jurídico, tendo em vista a inexistência de lei prevendo tal situação".

Para os estudiosos, o Poder Judiciário abandonou gradativamente a tecnocracia jurídica, agindo proati- 
vamente para alcançar à efetividade da norma jurídica e tornar possível e viável a prestação jurisdicional. Embora se discuta sobre a judicialização de processos e fatos sociais, envolvendo uma transferência de poder para juízes e tribunais.

Mesmo agindo em pró-atividade, diversas críticas são direcionadas ao papel exercido pelo Judiciário que, muitas vezes, evidencia o desequilíbrio jurídico, técnico e financeiro em relação às partes que se desigualam economicamente, cabendo ao poder judicante buscar essa equalização econômica como uma meta concretiva da função social do processo. E da mesma forma, Junior e Miranda ([s.d.], p. 1) entendem que o ativismo judicial, pautado na visão democracia que alia os poderes do Estado para atingir os fins sociais, pode, ainda, ser justificado pelo princípio do acesso à justiça, que proíbe a recusa da prestação jurisdicional (art. $5^{\circ}, \mathrm{XXXV}$ da CF).

Passos de Freitas (2009, p. 4) corrobora da preocupação de que o Judiciário "possa realizar a sua função de promover a pacificação social com a solução dos conflitos”, e demonstra a necessidade de atuação com equilíbrio, assim dispondo:

\begin{abstract}
Na administração, poderá o Judiciário: a) levar a Justiça a lugares distantes ou à periferia das grandes cidades, através de postos avançados ou juizados itinerantes; b) fortalecer os Juizados Especiais e Turmas Recursais; c) promovera interação e integração do Judiciário na sociedade (p. ex., cedendo o uso de espaços públicos para exposições ou congressos jurídicos); [...]. Nisto tudo, óbvio que há que se ter equilíbrio. (FREITAS, 2009, p. 4)
\end{abstract}

Inegável o fato de que o juiz assumiu um papel mais complexo do que aquele de interprete da norma jurídica aplicada ao caso concreto, pois, em determinadas situações a lei é silente e o julgador deve utilizar-se da interpretação mais sociológica e política, deixando de lado os dogmatismos, explorando as omissões do direito positivo para enfim, alcançar a solução que esteja em conformidade com as disposições e princípios constitucionais, enfatizando os chamados direitos fundamentais.

\section{A FUNÇÃO SOCIAL DO DIREITO CONTEMPORÂNEOE OPÓS-POSITIVISMO}

Imediatamente se faz necessária a interpretação dessa chamada função social do Direito, cabendo a colação do pensamento de Carvalho (2011, p. 3) que assim traduz o instituto:

\begin{abstract}
A função social do direito é um principio estruturante do ordenamento jurídico e encontra sede ao longo da historia do homem na terra, desde os tempos mais remotos. [...]. A função social do direito é o fim comum que a norma jurídica deve atender dentro de um ambiente que viabilize a paz social. 0 direito sempre teve uma função social.
\end{abstract}

Esclarecedoras são as palavras de Carvalho (2011, p. 4) que justificam o papel da norma jurídica que é sempre o "de viabilizar o alcance da paz social, objetivando humanizar as relações jurídicas, harmonizando os direitos e garantias do indivíduo", enquanto resta a convicção de que a teoria em questão fornece elementos para a realização e consolidação dos direitos mais embrionários da pessoa humana, num contexto de dignidade.

Racy (2010, p. 43) é categórica ao afirmar sobre o papel do Poder Judiciário com relação à função social exigida pela coletividade, inclusive na postura e especificamente nos julgados, e que estes possam traduzir a verdadeira efetividade da justiça. E sobre o tema em apreço, se manifesta:

\begin{abstract}
Função social é a que provém da sociedade, que dela emana e que, como se viu até agora, é mutável. Enquanto no Estado liberal consistia na segurança e no Estado de bem-estar social no acesso à justiça, no Estado contemporâneo, ela se define pela manutenção da sobrevivência do todo.A moralidade da função descrita está na sua legitimidade. Um juiz ético é aquele que realiza a prestação jurisdicional de acordo com a finalidade estabelecida por seus cidadãos.
\end{abstract}

A sociedade moderna cobra maior celeridade nas decisões judiciais, atribuindo a morosidade ao Poder 
Judiciário que contraria a buscada função social na conclusão das demandas, importando adotar a solução mais apta e mais justa às decisões.

Para Nobre Fraga ([s.d.], p. 1) o chamado "Estado Humanista tem ganhado bastante destaque em relação à força da jurisprudência como fonte do Direito", e isso demonstra ser uma verdadeira forma de mudança e a abertura de novos horizontes para o Direito Público e Privado, garantindo-se uma prestação jurisdicional cada vez mais equânime e proporcional, colocando em voga a função social dos institutos jurídicos, e afirma que:

\begin{abstract}
Já é sabido que o mero Estado Democrático está sendo superado pelo Estado Humanista de Direitos e Garantias Fundamentais, ou ainda Estado Constitucional de Direito ou similar, que inaugura uma nova era do pensamento jurídico-doutrinário, seja ele principalmente em função da efetiva aplicação dos direitos humanos, pois fundamentais, às relações entre particulares e entre o Estado e estes. 0 princípio da dignidade assume relevância ímpar neste panorama que se caracteriza por uma completa modificação na maneira de pensar o Direito e, portanto, na forma de aplicá-lo. (FRAGA, [s.d.], p. 1).
\end{abstract}

Autores chegam a afirmar que o pós-positivismo traz no seu cerne a composição das duas correntes de pensamento para o Direito, o jusnaturalismo e o positivismo. E para Carvalho Fernandes e outros autores $(2011$, p. 6) a maneira de pensar o Direito mudou, afinal para o autor o positivismo não mais foi capaz de construir respostas para os questionamentos jurídicos contemporâneo, e destaca:

As principais características desse novo posicionamento teórico podem ser identificadas, em suma, como a) a abertura valorativa do sistema jurídico e, sobretudo, da Constituição; b) tanto princípios quanto regras são considerados normas jurídicas; c) a Constituição passa a ser o locusprincipal dos princípios; e d) o aumento da força política do Judiciário em face da constatação de que o intérprete cria norma jurídica. Um grande desafio está lançado, o de buscar a justiça dentro de uma sociedade pluralista.

Diante da sinalização por parte da doutrina especializada, não se pode afastar o fato de que o pós- -positivismo promoveu o processo de renovação na discussão acadêmica e na percepção e abordagem dos Tribunais a respeito do tema, que inegavelmente se reveste de extrema importância para o Direito e se mostra como sendo uma barreira para a atuação estatal: os chamados direitos fundamentais.

Conceituando os direitos fundamentais, Gilmar Mendes (2002, p. 2) compreende a sua importância para a proteção de direitos subjetivos frente à intervenção do Poder Público, a saber:

Enquanto direitos subjetivos, os direitos fundamentais outorgam aos titulares a possibilidade de impor os seus interesses em face dos órgãos obrigados. Na sua dimensão como elemento fundamental da ordem constitucional objetiva, os direitos fundamentais - tanto aqueles que não asseguram, primariamente, um direito subjetivo, quanto aqueloutros, concebidos como garantias individuais - formam a base do ordenamento jurídico de um Estado de Direito democrático.

Indubitável, portanto, que a função social do Direito se enquadra na proposta de renovação decorrente da subsunção do fato à norma, tanto pela célere mutabilidade do fato social no mundo contemporâneo, influenciado pelo processo de globalização de culturas e significados, quanto pela readequação dos julgados que demandam a apreciação de conceitos extrajurídicos. Pois, tem sido uma exigência natural a formação humanística do magistrado, além da preocupação de aprofundar-se nas ciências sociais com vistas a sua correta e imediata inserção no sistema pós-positivista.

\section{CONCLUSÃO}

Verifica-se na pesquisa que o pós-positivismo não desconsidera a importância do Direito Positivo, mas busca torná-lo mais flexível e mais viável aos conclamos da sociedade, ao adotar a aplicação de princípios, tais como, a razoabilidade e a proporcionalidade.

Diante dessa abordagem, torna-se pontual que no momento da aplicação e da interpretação do Direito, o 
julgador não deve olvidar dos supramencionados valores que são imprescindíveis à ordem jurídica, mas, deve ainda inserir a dignidade do homem como foco central para o alcance da verdadeira e justa prestação jurisdicional.

Da mesma forma os legisladores devem atentar para a aplicação e garantia da igualdade na lei, evitando conceber a criação de normas lesivas aos chamados direitos da personalidade.

Verificou-se no trabalho, ora apresentado, que as leis não abarcam todos os elementos e situações fáticas dos casos concretos que são trazidos à apreciação do Judiciário, permitindo ao magistrado que por meio da argumentação, aplique o afastamento da lei para poder utilizar-se da interpretação mais sociológica e política, deixando de lado os dogmatismos, explorando as omissões do direito positivo para enfim, alcançar a solução que esteja em conformidade com as disposições e princípios constitucionais, porém, sem tornar essa conduta uma regra.

A descoberta do pós-positivismo anunciou o surgimento da denominada terceira corrente explicativa do Direito, haja vista a insuficiência do jusnaturalismo e do positivismo em abarcar todas as situações fáticas que se insurgem na sociedade contemporânea.

Conclui-se que a sociedade contemporânea exige soluções urgentes e justas para os conflitos que dela se insurgem, e para isto tornou-se inaceitável a prática do Positivismo exacerbado como meio mais adequado e viável para obter resultados às lides oriundos do seio social.

\section{REFERÊNCIAS}

CARVALHO, Francisco José. A função social do Direito e a efetividade das Normas Jurídicas. Carta Forense. 2011. Disponível em: <http://www.cartaforense. com.br/conteudo/artigos/a-funcao-social-do-direito-e-a-efetividade-das-normas-juridicas/7940>. Acesso em: 23 jan. 2015
COELHO, Fábio Ulhoa. Para entender Kelsen, 4.ed, rev. São Paulo: Saraiva, 2001

DALLARI, Dalmo de Abreu. Humanismo Jurídico. [s.d.]. DHnet - direitos humanos na internet. Disponível em: <http://www.dhnet.org.br/direitos/militantes/dalmodallari/dallari20.html>. Acesso em: 22 jan.2015.

FERNANDES DE AQUINO, Sérgio Ricardo. Mediação como experiência de humanização do direito na pós-modernidade: inquietações a partir do pensamento complexo. 2011. Disponível em: <http://www.periodicoseletronicos.ufma.br/index.php/revistahumus/ article/view/1645>. Acesso em: 25 jan. 2015

FERNANDES, Ricardo Vieira de Carvalho. BICALHO, Guilherme Pereira Dolabella. Do positivismo ao pós-positivismo jurídico: 0 atual paradigma jusfilosófico Constitucional. 2011. Disponível em: <http://www2.senado.leg.br/bdsf/bitstream/handle/id/242864/000910796.pdf?sequence=1>. Acesso em: 27 jan. 2015

MENDES, Gilmar. Os direitos fundamentais e seus múltiplos significados na ordem constitucional. Revista Diálogo Jurídico, Salvador, n.10, jan. 2002. p.2.

MIRANDA, André Padoin, CARNEIRO JÚNIOR, Amilcar Araújo. 0 ativismo judicial como mecanismo efetivo da hermenêutica jurídica constitucional no moderno estado democrático de direito. [s.d.]. Disponível em: <http://www.unigran.br/revista_juridica/ed_atual/artigos/artigo04.pdf>. Acesso em: 20 jan. 2015

NADER, Paulo. Introdução ao estudo do direito. 34.ed. Rio de Janeiro: Forense, 2012.

NOBRE FRAGA, Luiz Felipe. A religião do pós-positivismo. Âmbito Jurídico. [s.d.], Disponível em: <http:// www.ambito-juridico.com.br/site/index.php?n_ link=revista_artigos_leitura\&artigo_id=6743>. Acesso em: 24 jan. 2015 
PASSOS DE FREITAS, Vladimir. Responsabilidade Social do Juiz e do Judiciário. Revista Consultor Jurídico, 13 set. 2009. Disponível em: <http://www.tre-rs.jus.br/arquivos/FREITAS_Responsabilidade_juiz. pdf.> Acesso em: 24 jan. 2015

PINTO E BORGO, Maria Celia Nogueira. Apontamentos sobre o positivismo jurídico, sua superação e o papel do juiz diante dos princípios no modelo pós-positivista. CONPEDI. Disponível em: <http://www.conpedi.org. br/anais/36/11_1098.pdf>. Acesso em: 21 jan. 2015

PISKE, Oriana. 0 desafio da magistratura ante as mudanças sociais e econômicas. Parte II. 2007. Disponível em: <http://www.tjdft.jus.br/institucional/ imprensa/artigos/2007/o-desafio-da-magistratura-ante-as-mudancas-sociais-e-economicas-parte-ii-juiza-oriana-piske>. Acesso em: 23 jan. 2015

RACY, VIvien. A função do Poder Judiciário no estado contemporâneo. The social functionoftheJudiciary in thecontemporarystate. Revista USCS. 2010. p.43. Disponível em: <http://seer.uscs.edu.br/index.php/revista_direito/article/view/1092/897>. Acesso em 25 jan. 2015.

RODRIGUES MACIEL, José Fábio. Formação Humanística em Direito: uma responsabilidade social. Carta Forense. 2012. Disponível em: <http://www.cartaforense.com.br/conteudo/artigos/formacao-humanistica-em-direito-uma-responsabilidade-social/8642>. Acesso em: 21 jan. 2015.

SILVA, Eduardo Farias. 0 pós-positivismo e o ativismo judicial. Conteúdo Jurídico, Brasília-DF: 15 out. 2010. Disponível em: <http://www.conteudojuridico. com.br/?artigos\&ver=2.29307\&seo $=1>$. Acesso em: 26 jan. 2015

VENOSA, Silvio de Salvo. Introdução ao estudo do direito: primeiras linhas. 3.ed. São Paulo: Atlas, 2010. professor da Graduação e da Pós Graduação do Curso de Direito da Universidade Tiradentes-SE. E-mail: marltonmota@hotmail.com 